\title{
Strontium and Lead Isotope Analyses for Determining the Geographic Origins of Grains
}

\author{
Kaoru Ariyama, ${ }^{* \dagger}$ Miyuki ShInOZAKI,* Akira KaWASAKI,** and Yoshiki IshIDA*** \\ *Tokyo Research Laboratory, Japan Grain Inspection Association, 1-2-1 Shiohama, Koto, \\ Tokyo 135-0043, Japan \\ **National Institute for Agro-Environmental Sciences, 3-1-3 Kannondai, Tsukuba, Ibaraki 300-2611, Japan \\ ***Cereal Science Research Center of Tsukuba, Nisshin Flour Milling Inc., 13 Ohkubo, Tsukuba, \\ Ibaraki 300-2611, Japan
}

\begin{abstract}
A rapid determination method of ${ }^{87} \mathrm{Sr} /{ }^{86} \mathrm{Sr}$ and $\mathrm{Pb}$ isotope $\left({ }^{204} \mathrm{~Pb},{ }^{206} \mathrm{~Pb},{ }^{207} \mathrm{~Pb}\right.$, and $\left.{ }^{208} \mathrm{~Pb}\right)$ ratios was applied to determining the geographic origin of grain crops. This new method is more economical in terms of both time and cost compared to conventional methods. We used samples of barley $(n=321)$, rice $(n=111)$, and wheat $(n=93)$ grown in various countries. ${ }^{87} \mathrm{Sr} /{ }^{86} \mathrm{Sr}$ versus $\mathrm{Sr}$ concentration plots for the barley and wheat showed differences between products from Australia and those from other countries. Graphs of the $\mathrm{Pb}$ isotope ratios, comprising 15 two-dimensional plots, gave rise to a particular distribution for each country of production. The presented method showed promise for determining the production countries of grains by using the isotope ratios of $\mathrm{Sr}$ and $\mathrm{Pb}$.
\end{abstract}

(Received January 25, 2011; Accepted May 31, 2011; Published July 10, 2011)

\section{Introduction}

The global trade in agricultural products is expanding, and global competition in this area is increasing. In many countries, agricultural products are labeled with their geographical origin, mainly for branding strategy purposes and to help consumers in their selection of foodstuffs. However, such labeling has sometimes been used fraudulently for financial gain. Therefore, techniques to prevent consumers or producers from suffering financial damage are required.

Studies have been conducted worldwide with the aim of determining the geographic origin of agricultural products; to this end, techniques based on various principles have been attempted. The factors used for origin determination were mineral composition, obtained by inductively coupled plasma (ICP) optical emission spectrometry, ${ }^{1-3}$ ICP mass spectrometry (MS), ${ }^{1-3}$ and X-ray fluorescence analysis, ${ }^{4,5}$ the isotope composition of light elements, ${ }^{6,7}$ such as $\mathrm{H}, \mathrm{C}, \mathrm{N}$, and $\mathrm{O}$, and the ratios of heavy elements, such as $\mathrm{Sr}^{6,8}$ and $\mathrm{Pb}^{9}$ Mineral composition is one of the most popular factors for determining a geographic origin, and mainly reflects in soil features, such as fertilization. The mineral composition is different for each crop, even if grown under the same soil conditions. Therefore, a large database is required on the mineral compositions of all the different crops if an origin-determining technique is to be developed for all target items. The isotope composition of light elements is another of the most popular factors. This reflects various features for different elements: humidity, latitude, altitude, and distance from the sea for $\mathrm{H}$ and $\mathrm{O}$, whether it is a $\mathrm{C} 3$ or $\mathrm{C} 4$ plant for $\mathrm{C}$, and fertilization for N. For this technique

$\dagger$ To whom correspondence should be addressed.

E-mail: k-ariyama@kokken.or.jp as well, a large database is required for developing an origin-determining technique for all target agricultural products, for the same reasons as for the mineral composition. In fact, the database required here would be much larger because there could be significant variation, even within the same production area.

The isotope ratios of heavy elements, including strontium (Sr) and lead $(\mathrm{Pb})$, have some advantages over other factors for determining geographic origin. The isotopes of heavy elements are hardly fractionated in the terrestrial ecosystem. There is no difference in the isotope ratio between parts of a crop, ${ }^{10,11}$ or between a crop and the exchangeable fraction in the soill, ${ }^{10,12}$ as long as the crop is grown under the same soil and water conditions. Voerkelius et al. reported that a ${ }^{87} \mathrm{Sr} /{ }^{86} \mathrm{Sr}$ database of surface water could be applicable to prediction of the geographic origin of honey and wheat. ${ }^{13}$ Thus, once a database of one crop had been constructed, it would be applicable to new crops grown in the given area.

The ${ }^{87} \mathrm{Sr} /{ }^{86} \mathrm{Sr}$ value differs depending on the geochronological and lithological characteristics. ${ }^{13}$ Because the ${ }^{87} \mathrm{Sr} /{ }^{86} \mathrm{Sr}$ of soil is reflected in any agricultural products grown on that soil, this value has already been applied to determining the geographic origin of agricultural products, such as brown rice, ${ }^{8}$ wheat, ${ }^{13}$ and fruit juice. ${ }^{14}$ Therefore, we used this ${ }^{87} \mathrm{Sr} /{ }^{86} \mathrm{Sr}$ for determining the geographic origin of agricultural products analyzed in this study.

Lead has been utilized in various applications by humans since ancient times. Since the 1940s, leaded gasoline to which alkyllead was added as an anti-knocking agent, was used and released into the atmosphere in large amounts throughout the world; presently it is no longer used in advanced countries. Nriagu and Pacyna estimated that the total amount of anthropogenic lead released into the environment is 17-times higher than that from natural sources, ${ }^{15}$ and Komárek estimated 
that this amount is at least from one to two orders of magnitude higher. ${ }^{16}$ Bollhöfer and Rosman reported the $\mathrm{Pb}$ isotope compositions in aerosols collected from across the world between 1994 and 1999, ${ }^{17,18}$ and different regions were broadly characterized by the geographical variations found. ${ }^{17,18}$ These reports suggested the possibility that anthropogenic lead would affect the $\mathrm{Pb}$ isotope compositions in agricultural products, and therefore, we applied $\mathrm{Pb}$ isotope ratios for the purpose of identifying the geographic sources of agricultural products.

Japan imports a large amount of food; its self-sufficiency rate was $40 \%$ in 2009. ${ }^{19}$ Moreover, for grains foodstuffs, the self-sufficiency rate was only $28 \%$ in $2007 .{ }^{20}$ Thus, we targeted grains (barley, rice, and wheat) in this study, and attempted to determine their countries of production by using the rapid determination method of those isotope ratios developed in a previous study. ${ }^{21}$

\section{Experimental}

\section{Samples}

We used samples of barley (Hordeum vulgare), rice (Oryza sativa), and wheat (Triticum aestivu and durum). The barley samples were grains of hulled barley and grains of naked barley without the hull, the wheat samples were grains of whole wheat without the hull, and the rice samples were grains of polished rice and brown rice without the hull.

We used 321 samples of barely, the production areas of which were 42 prefectures in Japan $(n=221)$, Australia $(n=50)$, the United States $(n=20)$, and Canada $(n=30)$ (Table S1, Supporting Information). Of the samples from Australia, five were from Western Australia (WA), three were from New South Wales (NSW), three were from Victoria (VIC), six were from South Australia (SA), and the others were of unknown origin (Table S1). The rice (111 samples) were produced in 36 prefectures in Japan $(n=58)$, Australia $(n=4)$, the United States $(n=11)$, China $(n=31)$, and Thailand $(n=7)$ (Table S2, Supporting Information). The wheat (93 samples) were produced in 13 prefectures or districts in Japan $(n=44)$, Australia $(n=16)$, the United States $(n=21)$, and Canada $(n=12)$ (Table S3, Supporting Information). Of the samples from Australia, nine were a type of Australian Standard White (ASW) wheat with medium protein content, and seven were a type of Prime Hard $(\mathrm{PH})$ wheat with high protein content (Table S3).

The included grain samples were not those from the Okinawa islands of the southernmost prefecture in Japan. Each of the samples was taken from a different lot.

\section{Methods}

Determinations of $\mathrm{Sr}$ and $\mathrm{Pb}$ isotope ratios and $\mathrm{Sr}$ concentrations were carried out by following the procedure, as described in a previous study. ${ }^{21}$ The samples were washed with ultrapure water and analyzed in grains without pulverization. Barley (2.5 g), rice (10 g), and wheat (5 g) were used for acid digestion with $\mathrm{HNO}_{3}$ and $\mathrm{H}_{2} \mathrm{O}_{2}$. A barley sample of $2.5 \mathrm{~g}$, four rice samples of $2.5 \mathrm{~g}$, and two wheat samples of $2.5 \mathrm{~g}$ were put in digestion vessels (DigiTUBE; SCP SCIENCE) and digested using an acid digestion system with an automated thermal control unit (DigiPREP; SCP SCIENCE). ${ }^{21}$ The digested residue was dissolved in $\mathrm{HNO}_{3}$, transferred into a centrifuge tube, and diluted to a concentration of $8 \mathrm{~mol} \mathrm{~L}^{-1} \mathrm{HNO}_{3}$ in a volume of $6 \mathrm{~mL}$ for the barley and $12 \mathrm{~mL}$ for the rice and wheat. The solution was cooled to room temperature, and centrifuged at $3000 \mathrm{rpm}$ for $10 \mathrm{~min}$. The supernatant solution was loaded to a column packed with $\mathrm{Sr}$ resin $(50-100 \mu \mathrm{m}$; Eichrom Technologies) for an extraction chromatography to separate and concentrate $\mathrm{Sr}$ and $\mathrm{Pb}^{21}$ In extraction chromatography, $\mathrm{Sr}$ was eluted using $2 \mathrm{~mL}$ of $0.05 \mathrm{~mol} \mathrm{~L}^{-1}$ $\mathrm{HNO}_{3}$, and $\mathrm{Pb}$ was eluted with $2 \mathrm{~mL}$ of $6 \mathrm{~mol} \mathrm{~L}^{-1} \mathrm{HCl}^{21}$ In this extraction chromatography, no isotope fractionation was observed within the precision of this method. ${ }^{21}$ The concentrations of $\mathrm{Sr}$ and $\mathrm{Pb}$ in the eluted solutions were measured using a high-resolution (HR) ICPMS instrument (Element2; ThermoFisherScientific). ${ }^{21}$ The $\mathrm{Sr}$ and $\mathrm{Pb}$ eluted solutions were diluted to concentrations of $100-1000 \mu \mathrm{g} \mathrm{L}^{-1}$ using $0.05 \mathrm{~mol} \mathrm{~L}^{-1} \mathrm{HNO}_{3}$ and $1-10 \mu \mathrm{g} \mathrm{L}^{-1}$ using $6 \mathrm{~mol} \mathrm{~L}^{-1}$ $\mathrm{HCl}$, respectively, to match those of standard solutions.

The ${ }^{87} \mathrm{Sr} /{ }^{66} \mathrm{Sr},{ }^{204} \mathrm{~Pb} /{ }^{206} \mathrm{~Pb},{ }^{207} \mathrm{~Pb} / 206 \mathrm{~Pb}$, and ${ }^{208} \mathrm{~Pb} / 206 \mathrm{~Pb}$ ratios, and $\mathrm{Sr}$ concentrations were determined by HR-ICPMS following the procedure described in the previous study. ${ }^{21}$ In isotope ratio measurements, the standard reference material (SRM) 987 (NIST) for $\mathrm{Sr}$ and the SRM 981 (NIST) for $\mathrm{Pb}$ were repeatedly measured until stable values were observed before sample measurements, and also measured after sample measurements. Strontium and lead isotope ratios of samples were calculated by linear correction using obtained values of SRMs. ${ }^{21}$ The concentrations of $\mathrm{Sr}$ in the barley, polished rice, and wheat samples were determined by measuring the digested solutions diluted to $1 / 40,1 / 20$, and $1 / 40$, respectively, without the extraction chromatography. ${ }^{21}$ Each sample was analyzed just once.

Strontium and lead concentrations of blank solutions for isotope ratio measurements were typically $<2$ and $0.1-0.2 \mu \mathrm{g} \mathrm{L}^{-1}$, respectively. Strontium concentrations of extracted sample solutions were typically $500-4000,100-1000$, and $300-2500 \mu \mathrm{g} \mathrm{L}^{-1}$ for barley, rice and wheat, respectively. Lead concentrations of extracted sample solutions were typically $5-60,1-20$, and $3-40 \mu \mathrm{g} \mathrm{L}^{-1}$ for barley, rice, and wheat, respectively. The biases of ${ }^{87} \mathrm{Sr} /{ }^{86} \mathrm{Sr}$ ratios estimated from blank values were typically rates of $<0.006 \%$, because the isotope ratios of blank solutions were the average value of grains ( $\mathrm{ca}$. 0.709). The biases of $\mathrm{Pb}$ isotope ratios estimated from blank values were typically rates of $<0.04 \%$ for Japanese grains and $<0.06 \%$ for grains from overseas, because the isotope ratios of blank solutions were close to those of Japanese grains.

Intermediate precisions in the ${ }^{87} \mathrm{Sr} /{ }^{86} \mathrm{Sr},{ }^{204} \mathrm{~Pb} /{ }^{206} \mathrm{~Pb},{ }^{207} \mathrm{~Pb} / 206 \mathrm{~Pb}$, and ${ }^{208} \mathrm{~Pb} / 206 \mathrm{~Pb}$ ratios and $\mathrm{Sr}$ concentration analyses were obtained from inter-day variances of analyses carried out seven times on separate days at the same laboratory using barley, rice, and wheat powder samples.

\section{Results and Discussion}

\section{Intermediate precision of the method}

As the intermediate precision of the method, the relative standard deviations (RSDs) of the obtained ${ }^{87} \mathrm{Sr} /{ }^{86} \mathrm{Sr},{ }^{204} \mathrm{~Pb} /{ }^{206} \mathrm{~Pb}$, ${ }^{207} \mathrm{~Pb} /{ }^{206} \mathrm{~Pb}$, and ${ }^{208} \mathrm{~Pb} /{ }^{206} \mathrm{~Pb}$ ratios, and $\mathrm{Sr}$ concentrations were $0.036-0.081, \quad 0.11-0.53, \quad 0.11-0.21, \quad 0.17-0.34, \quad$ and $1.1-7.9 \%$, respectively (Table 1 ). The uncertainties in the obtained isotope ratio analyses were of the same levels as those of analyses using samples in grain form in the previous study. ${ }^{21}$ There were no significant differences in the uncertainties of the isotope ratios among the grain samples. However, the uncertainties in the Sr concentration analyses were larger for the rice sample, where the concentration was lower than in the other grain samples. The analytical uncertainties (RSDs) of the $\mathrm{Sr}$ and $\mathrm{Pb}$ isotope ratios were estimated to be around 0.055 and $0.22 \%$, respectively. 
Table 1 Intermediate precisions of $\mathrm{Sr}$ and $\mathrm{Pb}$ isotope ratios, and Sr concentration analyses of powder grains

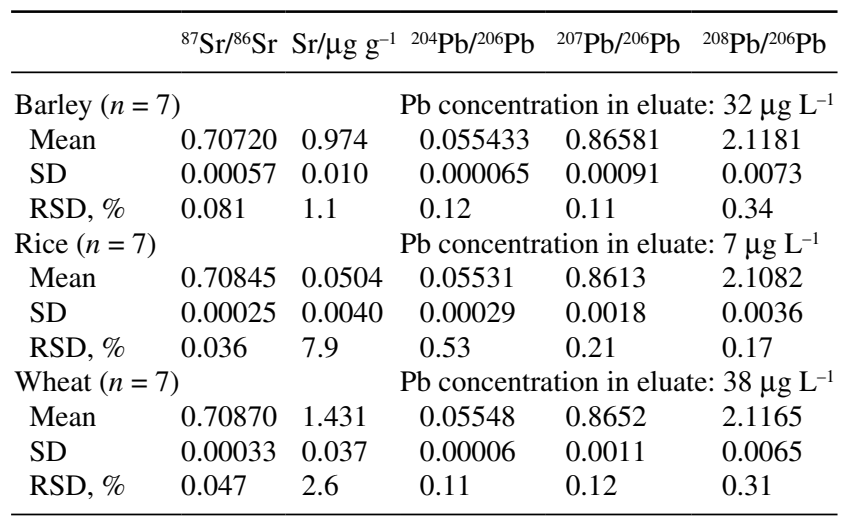

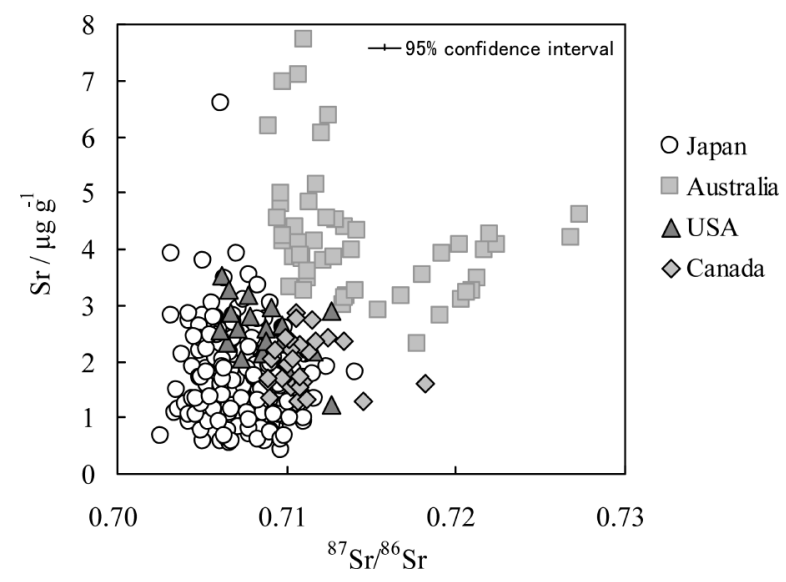

Fig. 1 Plot of ${ }^{87} \mathrm{Sr} /{ }^{86} \mathrm{Sr}$ versus Sr concentration for barley samples.

\section{${ }^{87} \mathrm{Sr} /{ }^{86} \mathrm{Sr}$ and $\mathrm{Sr}$ concentration}

In order to improve the accuracy of the geographic origin determination, scatter diagrams were prepared of ${ }^{87} \mathrm{Sr} /{ }^{86} \mathrm{Sr}$ versus $\mathrm{Sr}$ concentration (Figs. 1-3). The barley samples from Australia showed clear differences from the other countries in the plot (Fig. 1). Although the barley samples from the United States and Canada were distributed over small areas, some of them overlapped, and were distributed in the area of the barley samples from Japan (Fig. 1). Although the rice samples from Australia also showed differences from the other countries in the plot, some of them overlapped with the rice samples from Thailand (Fig. 2). The rice samples from China tended to have higher $\mathrm{Sr}$ concentrations than those from Japan, but some of these also overlapped (Fig. 2). The Chinese samples that had extremely high $\mathrm{Sr}$ concentrations were two of black rice. The rice samples from California, the United States, were distributed in a small region, but overlapped with some of these samples from Japan (Fig. 2), and samples from Thailand overlapped with those from Japan, Australia and China (Fig. 2). The ${ }^{87} \mathrm{Sr} /{ }^{86} \mathrm{Sr}$ ratios of the rice samples from Japan, Australia, the United States, and China were in agreement with the report of Oda et ll $^{8}$ The wheat samples from Australia also exhibited clear differences from the other countries in the plot (Fig. 3). In terms of the Australian samples, the ASW and PH wheat were clearly different from one another in the plot (Fig. 3). Some of the wheat samples from the United States and Canada overlapped, and also overlapped with a small number of wheat

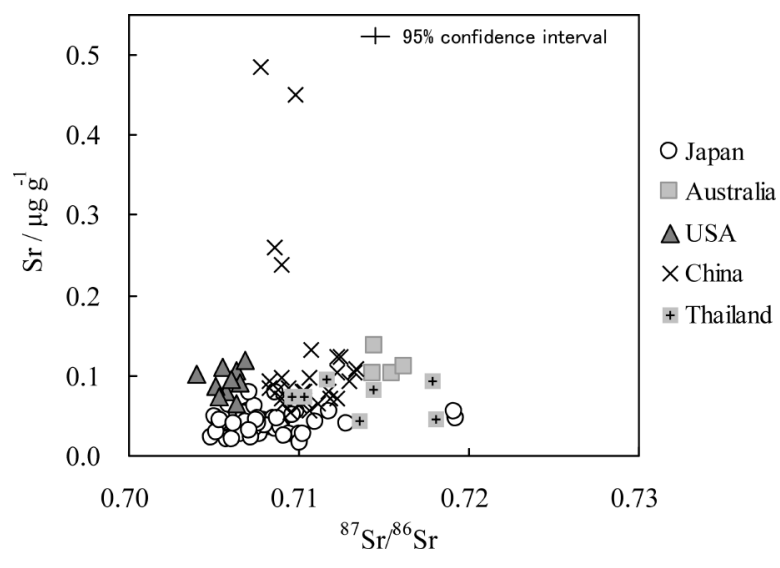

Fig. 2 Plot of ${ }^{87} \mathrm{Sr} /{ }^{86} \mathrm{Sr}$ versus $\mathrm{Sr}$ concentration for rice samples.

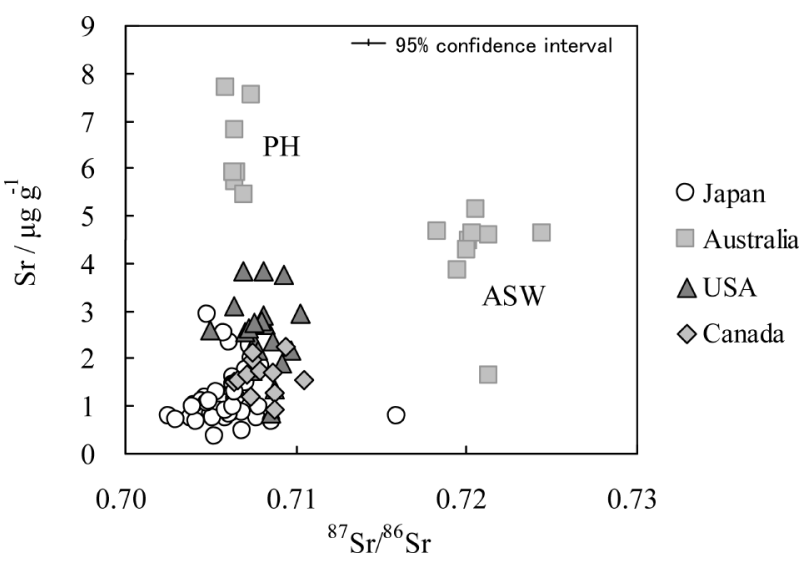

Fig. 3 Plot of ${ }^{87} \mathrm{Sr} /{ }^{86} \mathrm{Sr}$ versus $\mathrm{Sr}$ concentration for wheat samples. In the Australian wheat samples, ASW and PH stand for the brand names of Australian Standard White and Prime Hard, respectively.

samples from Japan (Fig. 3).

The grain samples from Japan tended to have lower ${ }^{87} \mathrm{Sr} /{ }^{86} \mathrm{Sr}$ ratios and $\mathrm{Sr}$ concentrations than those from other countries. The samples from Australia tended to have higher ${ }^{87} \mathrm{Sr} /{ }^{86} \mathrm{Sr}$ ratios and $\mathrm{Sr}$ concentrations, except for $\mathrm{PH}$ wheat, which had relatively low ${ }^{87} \mathrm{Sr} /{ }^{86} \mathrm{Sr}$ values $(0.706-0.707)$. The reason could be that the ASW and $\mathrm{PH}$ wheats were grown in different regions in Australia, which were the south area and Queensland, respectively.

The observed ${ }^{87} \mathrm{Sr} /{ }^{86} \mathrm{Sr}$ values and $\mathrm{Sr}$ concentrations of all samples are listed in Tables S1 - S3 in Supporting Information.

\section{$\mathrm{Pb}$ isotope composition}

In this study, we observed four $\mathrm{Pb}$ isotopes $\left({ }^{204} \mathrm{~Pb},{ }^{206} \mathrm{~Pb},{ }^{207} \mathrm{~Pb}\right.$, and ${ }^{208} \mathrm{~Pb}$ ), and obtained six isotope ratios. Therefore, we were able to construct 15 two-dimensional plots comprising these ratios for each grain (Figs. S1 - S3, Supporting Information). For barley, the ${ }^{208} \mathrm{~Pb} /{ }^{207} \mathrm{~Pb}$ versus ${ }^{206} \mathrm{~Pb} /{ }^{207} \mathrm{~Pb}$ and ${ }^{206} \mathrm{~Pb} /{ }^{204} \mathrm{~Pb}$ versus ${ }^{207} \mathrm{~Pb} /{ }^{204} \mathrm{~Pb}$ plots are shown in Fig. 4 . The barley samples from Japan were distributed over a small area, even though the samples were taken from all over Japan, except for Okinawa. The barley samples from Australia were distributed over a wide range, because the samples were from various regions in Australia where likely substances with different $\mathrm{Pb}$ isotope composition affected the barley samples. While the samples 

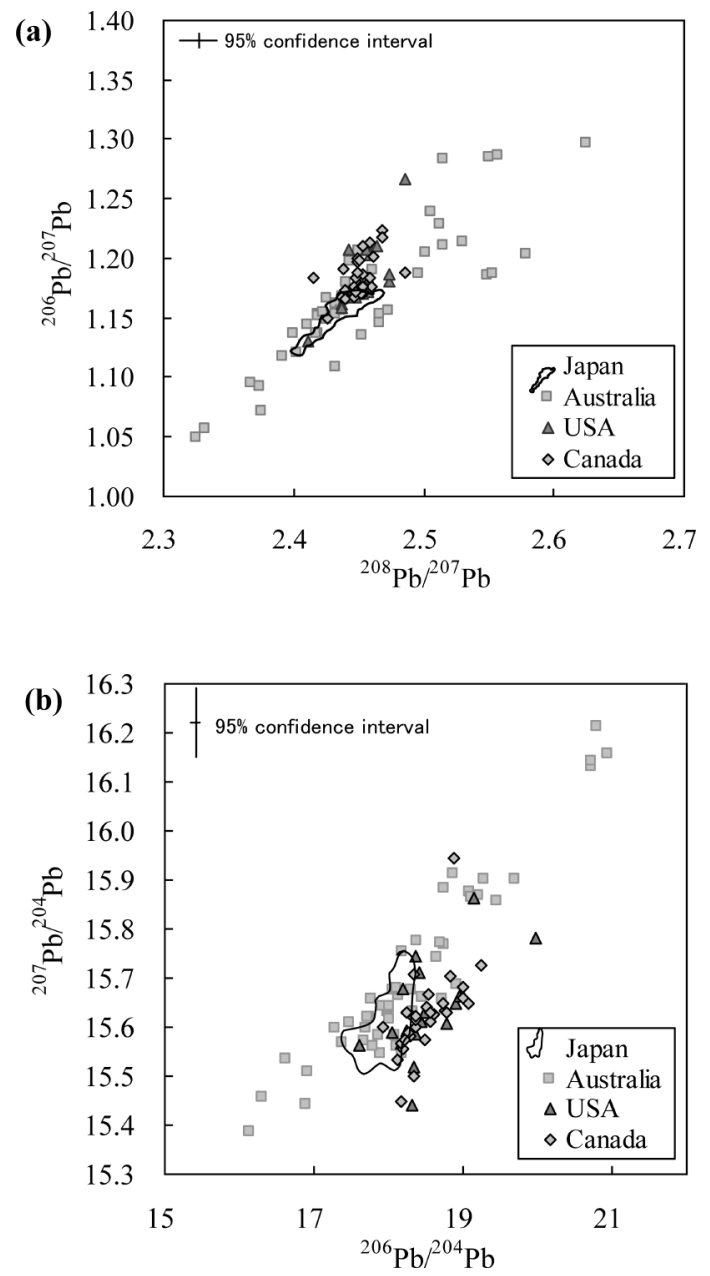

Fig. 4 Plots of (a) ${ }^{208} \mathrm{~Pb} /{ }^{207} \mathrm{~Pb}$ versus ${ }^{206} \mathrm{~Pb} /{ }^{207} \mathrm{~Pb}$ and (b) ${ }^{206} \mathrm{~Pb} /{ }^{204} \mathrm{~Pb}$ versus ${ }^{207} \mathrm{~Pb} /{ }^{204} \mathrm{~Pb}$ for barley samples. Japanese samples are within the closed curve. See Fig. S1 (Supporting Information) for all 15 two-dimensional color plots.

from the United States and Canada showed a particular distribution, and overlapped greatly, because the production areas of these two countries were in neighboring regions across the border where likely substances with the same $\mathrm{Pb}$ isotope composition affected the barley samples.

$\mathrm{A}{ }^{208} \mathrm{~Pb} /{ }^{207} \mathrm{~Pb}$ versus ${ }^{206} \mathrm{~Pb} /{ }^{207} \mathrm{~Pb}$ plot for the rice is shown in Fig. 5. The rice samples from Japan were distributed over the same small region as for the Japanese barley samples. The rice samples from Australia and the United States overlapped, and showed a particular distribution. The rice samples from China and Thailand also overlapped, and some of them overlapped with samples from Japan.

For wheat, a ${ }^{208} \mathrm{~Pb} /{ }^{207} \mathrm{~Pb}$ versus ${ }^{206} \mathrm{~Pb} /{ }^{207} \mathrm{~Pb}$ plot is shown in Fig. 6. The wheat samples from Japan were also distributed in the same small region as the barley and rice samples from Japan. The wheat samples from Australia were separated into ASW and $\mathrm{PH}$. The reason for this could be that the ASW and the PH wheats were grown in different regions in Australia, which were the south area and Queensland, respectively, and likely substances with the different $\mathrm{Pb}$ isotope composition affected the wheat samples. The wheat samples from the United States and Canada largely overlapped, and were in the same region as the barley samples for the same reason and production region as barley, respectively.

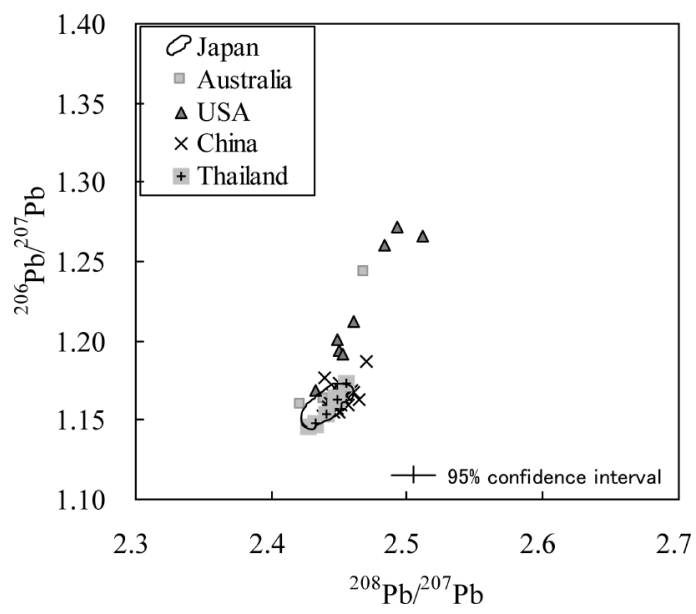

Fig. 5 Plot of ${ }^{208} \mathrm{~Pb} /{ }^{207} \mathrm{~Pb}$ versus ${ }^{206} \mathrm{~Pb} /{ }^{207} \mathrm{~Pb}$ for rice samples. Japanese samples are within the closed curve. See Fig. S2 (Supporting Information) for all of 15 two-dimensional color plots.

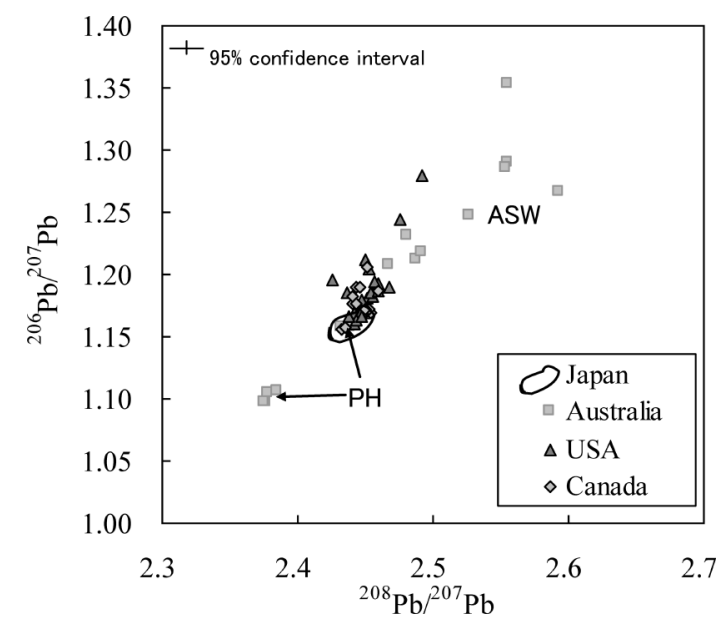

Fig. 6 Plot of ${ }^{208} \mathrm{~Pb} /{ }^{207} \mathrm{~Pb}$ versus ${ }^{206} \mathrm{~Pb} /{ }^{207} \mathrm{~Pb}$ for wheat samples. Japanese samples are within the closed curve. See Fig. S3 (Supporting Information) for all 15 two-dimensional color plots.

The grains from Japan fell into a limited $\mathrm{Pb}$ isotope region even though samples from all over Japan were used except for Okinawa. Thus, if the $\mathrm{Pb}$ isotope composition of a grain sample did not fall into this region, it could be considered that the sample did not originate in Japan, with the possible exception of Okinawa. Thus, the geographic origin could be determined if the isotope composition fell into the known region of a production country. Meanwhile, since the $\mathrm{Pb}$ isotope compositions of Japanese aerosols reported by Bollhöfer and Rosman were in the same region as those of the Japanese grains, ${ }^{18}$ these aerosols might have affected the $\mathrm{Pb}$ isotope compositions of grains grown in Japan.

The observed ${ }^{204} \mathrm{~Pb} /{ }^{206} \mathrm{~Pb},{ }^{207} \mathrm{~Pb} /{ }^{206} \mathrm{~Pb}$, and ${ }^{208} \mathrm{~Pb} / 206 \mathrm{~Pb}$ ratios of all samples are listed in Tables S1 - S3 in Supporting Information.

\section{Determination of the production country}

The plots of ${ }^{87} \mathrm{Sr} /{ }^{86} \mathrm{Sr}$ versus $\mathrm{Sr}$ concentration for barley and wheat could be used to differentiate samples grown in Australia from those produced in the other countries (Figs. 2 and 3). Two-dimensional plots of $\mathrm{Pb}$ isotope ratios were effective for 
confirming the results. However, the plots of ${ }^{87} \mathrm{Sr} /{ }^{86} \mathrm{Sr}$ versus $\mathrm{Sr}$ concentration could not be used to completely differentiate between the other countries for barley or wheat, or for any of the production countries for rice. However, plots of ${ }^{87} \mathrm{Sr} /{ }^{86} \mathrm{Sr}$ versus $\mathrm{Sr}$ concentration and two-dimensional plots of $\mathrm{Pb}$ isotope ratios could clearly differentiate between the production countries of some samples. Even if a sample was located in a region of several overlapping countries on some plots, if there was only one country demonstrated by the sample on every plot, then that country would be the geographic origin. For example, if a sample was in an overlapping region of Japan and the United States on the plot of ${ }^{87} \mathrm{Sr} /{ }^{86} \mathrm{Sr}$ versus $\mathrm{Sr}$ concentration, and in an overlapped region of Japan and Australia on every plot of $\mathrm{Pb}$ isotope ratios, the production country must be Japan.

A determination of the production country using a plot of ${ }^{87} \mathrm{Sr} /{ }^{86} \mathrm{Sr}$ versus $\mathrm{Sr}$ concentration and two-dimensional plots of $\mathrm{Pb}$ isotope ratios can be carried out in this manner. Although this method has high reliability, it was still not possible to determine the production countries of some samples. In particular, it was difficult to discriminate completely between samples from the United States and Canada because the production areas of these two countries were in neighboring regions across the border. Multivariate analyses, such as linear discriminant analysis and soft independent modeling of class analogy, were also carried out by using the ${ }^{87} \mathrm{Sr} /{ }^{86} \mathrm{Sr}$ ratio, $\mathrm{Sr}$ concentration, and $\mathrm{Pb}$ isotope ratios to determine the production countries of the grain samples. However, such multivariate analyses did not work because the analytical values of samples from some countries were located completely within the range of other countries, or did not have consistent patterns. Therefore, determining the geographic origin in the manner proposed in this work was more effective than using multivariate analyses. For those samples for which the production country could not be determined in this way, combination with other factors, such as multi-element concentration and light element isotope ratios, is required.

\section{Conclusions}

The countries for the production of various grains were determined using the isotope ratios of $\mathrm{Sr}$ and $\mathrm{Pb}$. Plots of the ${ }^{87} \mathrm{Sr} /{ }^{86} \mathrm{Sr}$ versus $\mathrm{Sr}$ concentration and two-dimensional plots of the $\mathrm{Pb}$ isotope ratios showed particular distributions for each country, and could be used to determine the production countries of some samples, such as Australian barley and wheat. The method employed in this study was demonstrated to be effective for rapid determination of $\mathrm{Sr}$ and $\mathrm{Pb}$ isotope ratios in grains. We expect that by increasing the amount data on the $\mathrm{Sr}$ and $\mathrm{Pb}$ isotope ratios, constructing a ${ }^{87} \mathrm{Sr} /{ }^{86} \mathrm{Sr}$ map of rice that represents the geographical distribution of ${ }^{87} \mathrm{Sr} /{ }^{86} \mathrm{Sr}$ ratios, and combining the data with other factors such as multi-element concentration, a distinct method with high reliability could be developed. are summarized in Tables S1-S3. Two-dimensional plots of the $\mathrm{Pb}$ isotope $\left({ }^{204} \mathrm{~Pb},{ }^{206} \mathrm{~Pb},{ }^{207} \mathrm{~Pb}\right.$, and $\left.{ }^{208} \mathrm{~Pb}\right)$ ratios of barley, rice and wheat samples are shown in Figs. S1 - S3. These materials are available free of charge on the Web at http://www.jsac. or.jp/analsci/.

\section{References}

1. A. Yasui and K. Shindoh, Bunseki Kagaku, 2000, 49, 405.

2. K. Ariyama, H. Horita, and A. Yasui, Anal. Sci., 2004, 20, 871.

3. K. Ariyama, H. Horita, and A. Yasui, J. Agric. Food Chem., 2007, 55, 347.

4. Y. Yanada, A. Hokura, K. Masuda, M. Mizuhira, and I. Nakai, Bunseki Kagaku, 2007, 56, 1053.

5. A. Otaka, Y. Yanada, A. Hokura, K. Matsuda, and I. Nakai, Bunseki Kagaku, 2009, 58, 1011.

6. S. Rummel, S. Hoelzl, P. Horn, A. Rossmann, and C. Schlict, Food Chem., 2010, 118, 890.

7. T. Korenaga, M. Musashi, R. Nakashita, and Y. Suzuki, Anal. Sci., 2010, 26, 873.

8. H. Oda, A. Kawasaki, and T. Hirata, Anal. Sci., 2001, 17, 627.

9. B. Médina, S. Augagneur, M. Barbaste, F. E. Grousset, and P. Buat-Ménard, Food Addit. Contam., 2000, 17, 435.

10. Y. Yokoo and T. Nakano, Annu. Rep., Inst. Geosci., Univ. Tsukuba, 1996, 22, 37.

11. E. Dambrine, M. Loubet, J. A. Vega, and A. Lissarague, Plant Soil, 1997, 192, 129.

12. A. Kawasaki and H. Oda, Jpn. J. Soil. Sci. Plant Nutr., 2005, 76, 579 .

13. S. Voerklius, G. D. Lorenz, S. Rummel, C. R. Quétel, G. Heiss, M. Baxter, C. Brach-Papa, P. Deters-Itzelsberger, S. Hoelzl, J. Hoogewerff, E. Ponzevera, B. M. Van, and H. Ueckermann, Food Chem., 2010, 118, 933.

14. S. Rummel, S. Hoelzl, P. Horn, A. Rossmann, and C. Schlicht, Food Chem., 2010, 118, 890.

15. J. O. Nriagu and J. M. Pacyna, Nature, 1988, 333, 134.

16. M. Komárek, V. Ettler, V. Chrastný, and M. Mihalevič, Environ. Inter., 2008, 34, 562.

17. A. Bollhöfer and K. J. R. Rosman, Geochim. Cosmochim. Acta, 2000, 64, 3251.

18. A. Bollhöfer and K. J. R. Rosman, Geochim. Cosmochim. Acta, 2001, 65, 1727.

19. Food self-sufficiency rate in 2009, Ministry of Agriculture, Forestry and Fishery of Japan, http://www.maff.go.jp/j/ press/kanbo/anpo/100810.html.

20. Cereal self-sufficiency rate in 2007, Ministry of Agriculture, Forestry and Fishery of Japan, http://www.maff.go.jp/j/ zyukyu/fbs/pdf/2007foreign-country2.pdf.

21. M. Shinozaki, K. Ariyama, A. Kawasaki, and T. Hirata, Bunseki Kagaku, 2010, 59, 1003.

\section{Supporting Information}

Details of the samples used in this study and analytical results 